\title{
8
}
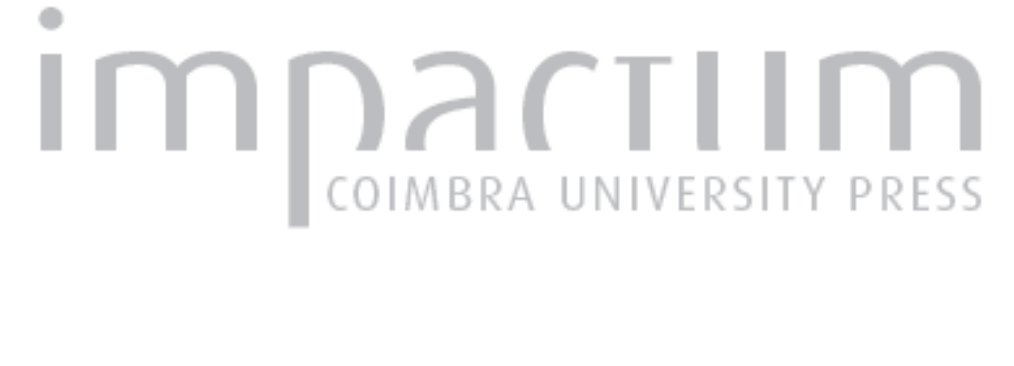
Os vestígios osteológicos humanos do Paleolítico Português: revisão bibliográfica e
análise dos dados
Autor(es):
Cruz, Cristina Barroso; Cunha, Eugénia
Publicado por: CIAS - Centro de Investigação em Antropologia e Saúde
URL persistente:
URI:http://hdl.handle.net/10316.2/28863
DOI:
DOI:http://dx.doi.org/10.14195/2182-7982_25_5
Accessed : $\quad$ 26-Apr-2023 07:38:46

A navegação consulta e descarregamento dos títulos inseridos nas Bibliotecas Digitais UC Digitalis, UC Pombalina e UC Impactum, pressupõem a aceitação plena e sem reservas dos Termos e Condições de Uso destas Bibliotecas Digitais, disponíveis em https://digitalis.uc.pt/pt-pt/termos.

Conforme exposto nos referidos Termos e Condições de Uso, o descarregamento de títulos de acesso restrito requer uma licença válida de autorização devendo o utilizador aceder ao(s) documento(s) a partir de um endereço de IP da instituição detentora da supramencionada licença.

Ao utilizador é apenas permitido o descarregamento para uso pessoal, pelo que o emprego do(s) título(s) descarregado(s) para outro fim, designadamente comercial, carece de autorização do respetivo autor ou editor da obra.

Na medida em que todas as obras da UC Digitalis se encontram protegidas pelo Código do Direito de Autor e Direitos Conexos e demais legislação aplicável, toda a cópia, parcial ou total, deste documento, nos casos em que é legalmente admitida, deverá conter ou fazer-se acompanhar por este aviso. 


\section{Antropologia Portuguesa}

Volume $24-25 \cdot 2007-2008$

Departamento de Antropologia | Universidade de Coimbra

\section{Dossier Temático \\ CLAUDE LÉVI-STRAUSS}




\title{
Os vestígios osteológicos humanos do Paleolítico Português: revisão bibliográfica e análise dos dados
}

\author{
Cristina Barroso Cruz, Eugénia Cunha \\ Departamento de Antropologia, \\ Universidade de Coimbra, Portugal \\ cbscruz@student.antrop.uc.pt
}

Resumo $\mathrm{O}$ estudo da evolução humana resulta da conjugação de várias áreas científicas, como a Arqueologia, esta caracterizando os contextos geológicos e socioculturais em cada época, e a Antropologia física, contribuindo para a interpretação dos dados fornecidos pelos vestígios osteológicos humanos. O Paleolítico assume-se como um dos períodos mais importantes no processo evolutivo humano, já que entre os 4,5 milhões de anos e os 10,000 anos, surgiram e extinguiram-se as formas préhumanas e humanas que estão na origem directa do Homo sapiens. Com o presente trabalho pretende-se compreender que tipo de material osteológico humano deste período existe em Portugal, por meio de uma intensa revisão bibliográfica, e quais as informações daí decorrentes para a compreensão da evolução humana. Os dados revelaram que os vestígios mais frequentes, atribuídos ao Paleolítico português, são os dentes e que os sub-adultos constituem os indivíduos mais representados. Todos os sítios arqueológicos com evidências osteológicas foram identificados em grutas da Estremadura portuguesa, sendo este padrão geográfico distinto do verificado para Espanha. As datações atribuídas aos Neandertais revelaram-se mais recentes do que noutros contextos europeus. Os vestígios osteológicos atribuídos ao Paleolítico português podem ajudar a compreender o padrão de ocupação do território durante a Pré-história.

Palavras-chave Paleolítico; vestígios osteológicos; evolução humana; antropologia; arqueologia.

Abstract The study of human evolution results from an interdisciplinary approach.
In that sense, Archaeology helps to define and characterize the chronological and
cultural context, and anthropological methods contribute to reveal the information
that human remains hold. The Palaeolithic is one of the most important periods of
the human evolution process. During the time frame that defines it - 4,5 million
years and 10,000 years - several hominid forms, directly related to Homo sapiens,
have appeared and became extinct. This paper's goal is to present the osteological
human remains found in Portuguese territory and attributed to the Palaeolithic period.
To do so, a bibliographic review was carried out. The gathered data allowed an
overview of the climate, geomorphology and ecology of Portuguese territory, and 
its role on the human evolutionary process. Frequency analyses revealed that teeth are the most frequent remains and sub-adults are the most represented individuals. All remains where found in caves in the Portuguese Estremadura. The geographical and clustered pattern of the archaeological sites differ from what is found in Spain. Neanderthal remains in the Iberian Peninsula revealed a late occupation of the territory when compared with other European contexts. The osteological human remains from the Portuguese Palaeolithic can offer an insight on the territory occupation during pre-history.

Key words Palaeolithic; human remains; human evolution; anthropology; archaeology.

\section{Introdução}

O estudo da Evolução Humana implica a articulação de um conjunto de áreas científicas diversificadas, como seja a Arqueologia, a Geologia e a Química que permitem, quando conjugadas, desvendar um pouco mais do mistério que envolve a espécie humana. Neste quadro interdisciplinar, a Antropologia assume um papel de relevo, já que contribui para a interpretação dos vestígios osteológicos deixados pelos nossos antepassados.

Um dos períodos mais importantes para o processo evolutivo humano foi o Paleolítico, o mais antigo dos três períodos da Pré-história, uma vez que durante esta época surgiram, e extinguiram-se, os antepassados humanos mais directos, como sejam os Australopithecus e as várias espécies do género Homo (Arsuaga, 2001; 2003; Jones et al., 1992; Jurmain et al., 2004; Lewin e Foley, 2004). O termo Paleolítico (do grego Palaiós antigo; lithos - pedra) surgiu no século XIX por John Lubbock e estava associado ao conceito de "Pedra lascada", por ser o vestígio deixado pelos seres humanos mais comummente encontrado neste período. Apesar desta ser uma definição essencialmente tecnicista e anacrónica, mantém-se até aos dias de hoje (Bicho, 2006; Cunha-Ribeiro, 1990). Este período préhistórico caracteriza-se essencialmente pelo clima glaciar que afectou não só a geomorfologia do território, mas também teve influência nas rotas migratórias das formas humanas (Arsuaga, 2001; Bicho, 2006; Cardoso, 2002; Cunha-Ribeiro, 1990; Raposo, 1993a). A maioria dos autores considera que o Paleolítico está dividido em três sub-períodos: inferior, médio e superior (Bicho, 2006; Cunha-Ribeiro, 1990; Cardoso, 2002; Raposo, 
1993a). A divisão tripartida do tempo é uma ferramenta científica baseada no conceito "início-desenvolvimento-fim" e, neste caso, assenta não só na evolução das técnicas de produção de instrumentos mas, também, no tipo de sociedade e espécie de hominíneo existente em determinado momento (Raposo, 1993a; 1993b).

O Paleolítico Inferior terá tido o seu início há 4,5 milhões de anos, para terminar há 100,000 anos. Caracteriza-se pela produção do primeiro instrumento em pedra ainda no continente Africano e com a produção de bifaces na Europa (Arsuaga, 1999; Bicho, 2006; Cardoso, 2002; Cunha-Ribeiro, 1990). O período intermédio, ou Paleolítico Médio, está compreendido entre os 250,000 e os 40,000 anos e será o mais complexo dos três sub-períodos estando directamente associado às várias espécies do género Homo, sendo marcado pelo desenvolvimento de técnicas de produção de ferramentas líticas bastante diversificadas (Bicho, 2006; Cardoso, 2002; Cunha-Ribeiro, 1990). O Paleolítico Superior, balizado entre os cerca de 40,000 e os 10,000 anos, caracteriza-se pelo desenvolvimento de vários técno-complexos (Chatelperronense, Aurignacense, Gravettense, Solutrense e Magdalenense), terminando com o final da última glaciação europeia, a glaciação de Würm (Bicho, 2006; Cunha-Ribeiro, 1990; Finlayson et al., 2006).

Em Portugal são vários os contextos arqueológicos com vestígios associados ao Paleolítico (Bicho, 2006), contudo, o número de locais em que se detectaram restos osteológicos humanos é bem mais reduzido.

O objectivo do presente artigo, que resultou do trabalho desenvolvido no âmbito do Mestrado em Evolução Humana, é efectuar uma revisão bibliográfica das publicações em que são relatadas as descobertas de vestígios osteológicos humanos encontrados em território nacional e atribuídos ao Paleolítico, permitindo um acesso facilitado à informação dispersa, cuja consulta implicaria a mobilização de um conjunto de recursos humanos e materiais consideráveis. Como resultado deste esforço, sistematizaram-se os dados antropológicos tendo em conta as características mais relevantes. Esta sistematização possibilitou a realização de uma análise paleodemográfica, estatística e geográfica. Este trabalho contempla igualmente uma vertente crítica sobre os novos e os antigos dados publicados. Em consequência do processo analítico, algumas questões foram discutidas, como, por exemplo, a compreensão da ocupação do território nacional e Ibérico ao longo deste período, e a importância do contexto português no estudo da evolução 
humana. Por fim, os resultados obtidos foram debatidos e comparados, tendo por base contextos com elementos semelhantes.

\section{Metodologia}

O presente artigo resulta da combinação de um conjunto diversificado de metodologias. Numa primeira fase, efectuou-se uma intensa pesquisa bibliográfica com o intuito de reunir todas as informações que pudessem estar relacionadas com os vestígios osteológicos encontrados em território português e atribuídos ao Paleolítico. Quando, a partir das publicações, não foi possível aceder a toda a informação que permitisse a clara compreensão dos dados relativos ao vestígio e/ou ao contexto da sua descoberta, procurou-se entrar em contacto com os investigadores que, de forma directa ou indirecta, estivessem relacionados com o estudo de um determinado espólio. Numa segunda etapa, foi realizada a análise estatística dos dados, a que se seguiu um estudo paleodemográfico efectuado de forma indirecta com base nos elementos extraídos da pesquisa. Por fim, tendo em conta todos os elementos reunidos, foi feita a discussão dos resultados obtidos.

\section{Os vestígios osteológicos do Paleolítico}

Optou-se por apresentar os dados (Tabela 1) de forma sistemática para, por um lado, ser possível aceder de um modo rápido e simples à informação essencial de cada um dos vestígios e, por outro, não repetir os conteúdos dos estudos de material e contextos que foram publicados mais recentemente e que ao nível científico já foram revistos. Os dados serão apresentados cronologicamente (do vestígio com datação mais antiga para o mais recente), especificando a localização, a tipologia do vestígio osteológico, a datação, a espécie de hominíneo que lhe é atribuída, a referência da publicação e as observações consideradas mais relevantes. 


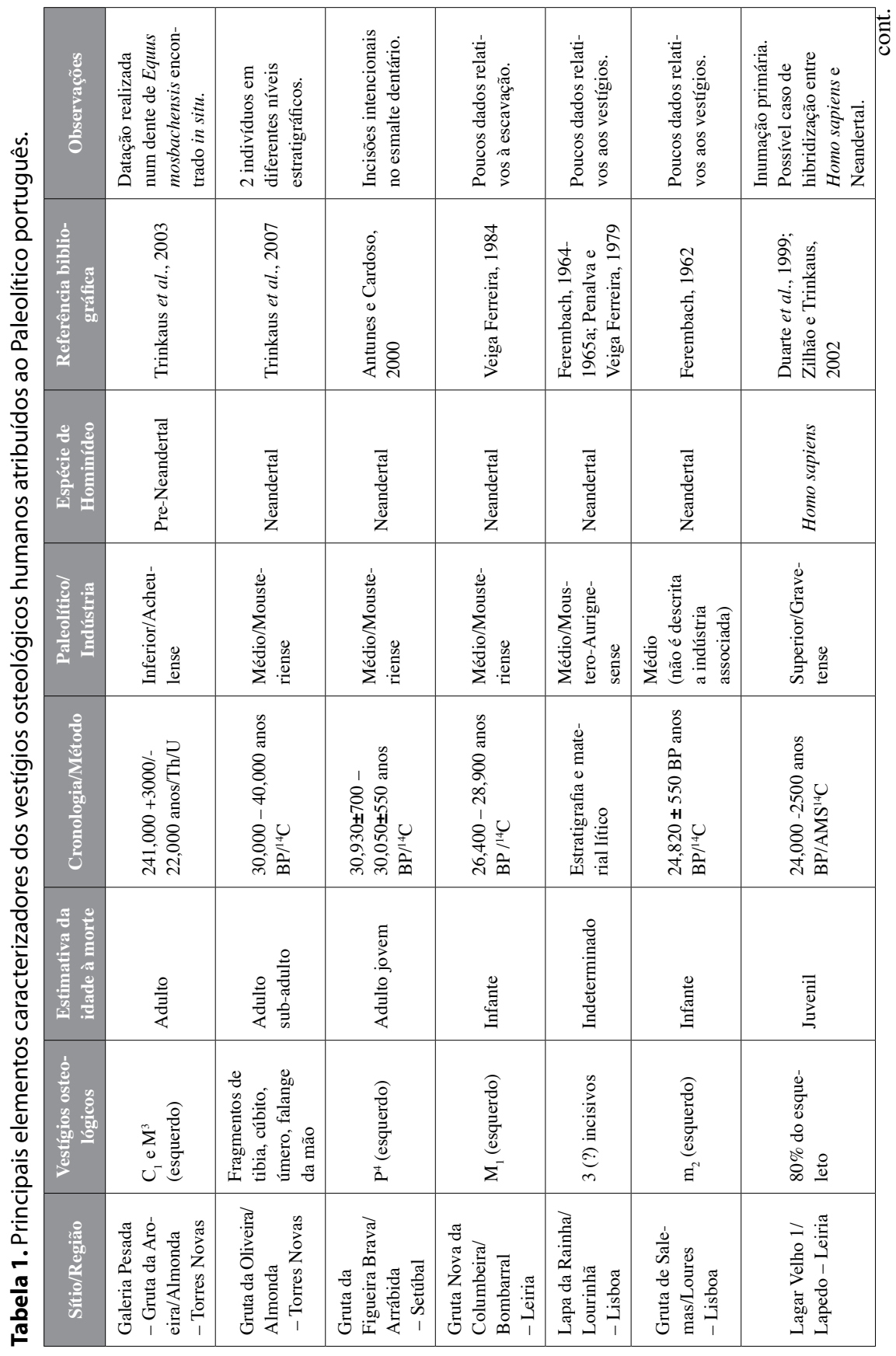




\begin{tabular}{|c|c|c|c|c|c|c|}
\hline 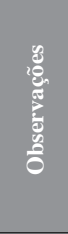 & 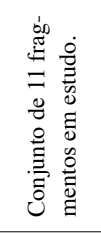 & 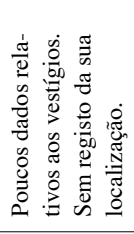 & 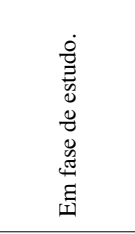 & 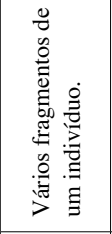 & 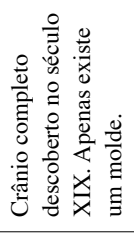 & 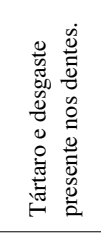 \\
\hline 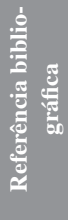 & 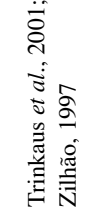 & 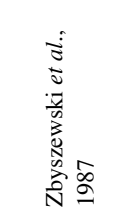 &  & 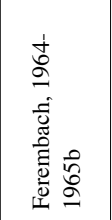 & 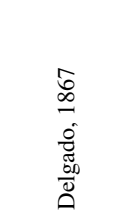 & 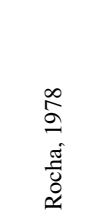 \\
\hline 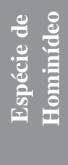 & 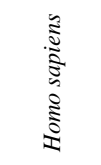 & 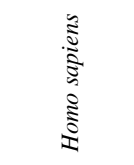 &  & 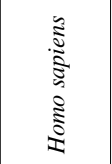 & 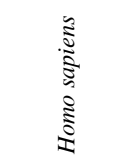 & 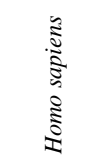 \\
\hline 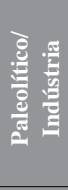 & 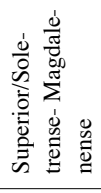 & 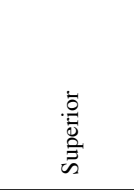 & 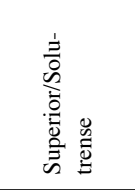 & 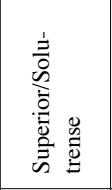 & 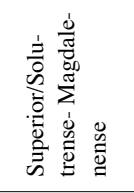 & 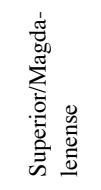 \\
\hline $\begin{array}{l}\frac{0}{0} \\
\frac{5}{00} \\
\frac{\pi}{00} \\
\frac{0}{00} \\
\frac{0}{0} \\
\frac{0}{0}\end{array}$ & 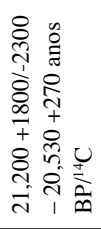 & 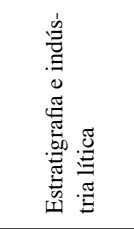 & 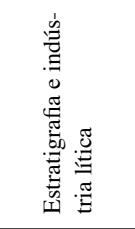 &  & 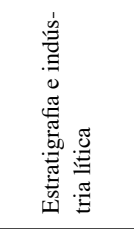 & 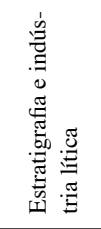 \\
\hline 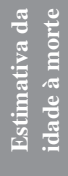 & 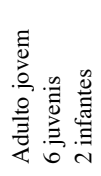 & 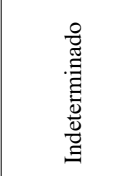 &  & $\begin{array}{l}\overline{\overline{0}} \\
\stackrel{\Xi}{\Xi}\end{array}$ & $\frac{\stackrel{9}{3}}{\frac{3}{4}}$ & $\frac{\frac{O}{3}}{\frac{7}{4}}$ \\
\hline 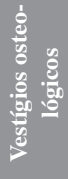 & 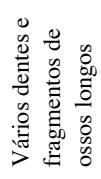 & 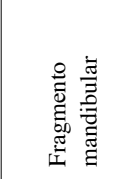 & 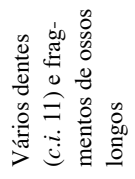 & 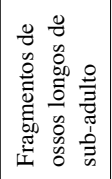 & 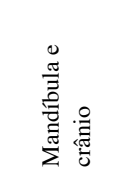 & 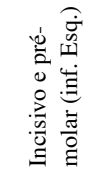 \\
\hline 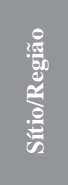 & 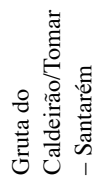 & 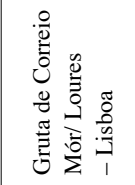 & 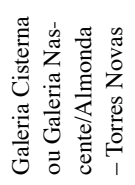 & 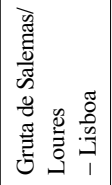 & 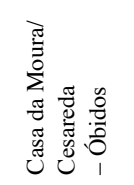 & 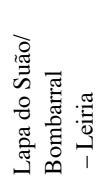 \\
\hline
\end{tabular}


Nos dados apresentados anteriormente, existem alguns elementos que importa referir e que resultaram da pesquisa realizada.

O complexo cársico do Almonda será um dos mais importantes contextos arqueológicos do Paleolítico. Nele encontram-se vestígios de todos os sub-períodos do Paleolítico, mas de relevar é o facto de ser numa das suas grutas - Galeria Pesada - que foi detectado o mais antigo vestígio osteológico humano. Também deste contexto cársico - na Gruta da Oliveira - foi resgatado o conjunto de vestígios mais numeroso do Paleolítico Médio (Trinkaus et al., 2003; 2007).

Os vestígios encontrados na Gruta da Figueira Brava foram apresentados em duas publicações, uma de 1990-1991 de Miguel Telles Antunes, e uma outra de 2000 do mesmo autor em co-autoria com João Luís Cardoso. Se na primeira publicação - apesar da escassez de elementos que inviabiliza a fiabilidade das avaliações antropológicas - é exposto um conjunto osteológico mais alargado (um dente, um metatársico e uma falange da mão), bem como uma estimativa da idade à morte (17 anos), a diagnose sexual (masculino) e evidências de um possível comportamento antropofágico; na publicação mais recente, apenas o dente é apresentado, caindo por terra as outras inferências. Os ossos curtos referidos apresentam semelhanças importantes com os seus correspondentes em ursídeos. A incerteza em relação à classificação taxonómica destas peças terá estado na origem da não inclusão deste material na publicação mais recente. Tendo em conta estes dados, apenas podemos considerar o pré-molar como correspondendo a um indivíduo do género humano que pela datação (feita pelo ${ }^{14} \mathrm{C}$ e repetida através do Th/U, esta última não se revelando conclusiva, atendendo ao desvio padrão obtido) seria possivelmente Neandertal (Antunes, 1990-1991; Antunes e Cardoso, 2000). Este dente apresenta uma outra característica importante, na medida em que foi identificado um conjunto de 10 incisões intencionais - tendencialmente verticais, separadas por cerca de $1 \mathrm{~mm}$ e com um comprimento de $3 \mathrm{~mm}$ - que terão sido realizadas post mortem, já que estas alterações se encontram na faceta de contacto com o primeiro molar superior (Antunes e Cardoso, 2000).

A Gruta da Columbeira distingue-se das restantes, por se pensar que possa ter sido a base de um acampamento de Neandertais, dado o espólio osteológico lá encontrado, mas também pela grande quantidade e diversidade de material arqueológico associado (Raposo e Cardoso, 1998). Para Raposo e Cardoso (1998), após a descoberta deste espaço pelos hominíneos 
pré-históricos, dá-se uma ocupação e utilização esporádica que decorre de uma forma rudimentar de exploração económica, no que à produção lítica e gestão de recursos diz respeito. Mais tarde, passa a existir uma ocupação mais frequente da gruta, sendo a este momento que os autores atribuem a existência de um acampamento. Após este período, a ocupação do espaço deu-se de uma forma muito mais fortuita.

Os dentes identificados na Lapa da Rainha têm apenas, em nota de rodapé, a referência a uma consulta informal de Denise Ferembach que os terá classificado como sendo incisivos humanos, e dado o contexto cronológico foram atribuídos ao homem de Neandertal. A imagem disponível na publicação deste achado (Almeida et al., 1970), não permite confirmar a classificação atribuída, já que a forma de pelo menos um deles, não se aproxima da tipologia conhecida para o género Homo, podendo pertencer a outro primata.

Dos vestígios encontrados na Gruta de Salemas existem dois artigos quase contemporâneos (Ferembach, 1962; 1964-1965b) que referem a existência de um dente de sub-adulto atribuído ao Paleolítico Médio e um conjunto de ossos longos e fragmentos cranianos que pertencem ao Paleolítico Superior. Apesar de não ser dito claramente, é possível inferir que o conjunto osteológico mais recente pertencerá a apenas um indivíduo subadulto. Contudo, fica por esclarecer se estes dois achados pertencem a um mesmo sítio arqueológico ou não.

O Abrigo do Lagar Velho será um dos sítios pré-históricos mais conhecidos em Portugal, por nele ter sido encontrado o único enterramento primário para este período na Península Ibérica e por estar associado ao debate do possível cruzamento entre Neandertais e Homo sapiens. No que diz respeito aos dados da antropologia de campo, este enterramento dá-nos pistas importantes relativas aos rituais funerários deste período da Pré-história, dando a possibilidade de inferir sobre a estrutura dos núcleos sociais no momento de transição do Paleolítico Médio para o Paleolítico Superior (Duarte et al., 1999).

De acordo com Trinkaus e colaboradores (2001), a Gruta do Caldeirão teria servido como local de fabrico de utensílios e de área para o processamento da caça obtida, podendo esporadicamente ter também servido de abrigo para pequenos grupos familiares durante curtos períodos de tempo. Desta gruta resultou o acervo mais numeroso e diversificado de todos aqueles atribuídos a este período cronológico. 
Da Gruta de Correio Mór, foi apenas encontrada uma referência publicada relativa ao vestígio aí posto a descoberto - um fragmento mandibular bastante completo (Zbyszewski et al., 1987). Para além deste registo, foram também recuperados apontamentos académicos não publicados que nos levam a crer que este vestígio terá, de facto, sido encontrado neste contexto.

O crânio da Gruta da Casa da Moura é talvez o vestígio reavido há mais tempo. A publicação que refere esta descoberta, apesar de ser de 1867 (por Nery Delgado), permitiu, dado o seu carácter descritivo, aos investigadores contemporâneos confirmarem que este achado pertencia de facto ao Paleolítico Superior (Zilhão, 1993).

Relativamente ao material divulgado ao longo da primeira metade do século XX não há, na maioria dos casos, registos dos seus locais de depósito. Efectuou-se um esforço para aceder ao espólio, todavia, tal nem sempre foi possível, por se encontrar em paradeiro desconhecido (Gruta da Casa da Moura, Gruta de Correio Mór), por estar em fase de estudo (Gruta da Oliveira, Gruta do Caldeirão), por integrar uma exposição noutro país (o material do Abrigo do Lapedo), outros por não se encontrarem acessíveis para observação apesar de se saber o seu local de armazenamento (Gruta da Figueira Brava na Academia de Ciências de Lisboa) ou simplesmente por não ter sido dada uma resposta em tempo útil, apesar de se saber que se encontram em depósito no Museu Nacional de Arqueologia e IGESPAR. Foi, no entanto, possível ver os dentes descobertos na Gruta da Lapa do Suão, os quais estão em depósito no Departamento de Antropologia da Universidade de Coimbra.

\section{Análise dos dados}

A amostragem obtida permitiu uma análise das frequências de forma a possibilitar a caracterização paleodemográfica dos vestígios referenciados. A primeira abordagem diz respeito à distribuição por tipologia. Para tal, o material osteológico foi agrupado nas seguintes categorias: "Crânio", "Ossos longos e curtos" e, por fim, "Mandíbula, Maxilar e Dentes". O resultado da distribuição dos dados está representado na Figura 1. 




Figura 1. Distribuição dos vestígios osteológicos humanos atribuídos ao Paleolítico português por tipologia de osso.

Procurou-se também perceber que tipo de distribuição por faixa etária o material atribuído ao Paleolítico apresentava (Figura 2). Para melhor compreensão criaram-se 5 categorias: "Infante" ( $0-5$ anos), "Juvenil" (6- 15 anos), "Adulto jovem" (16-25 anos), "Adulto" (> 25 anos), "Indeterminado" (idade não referida pelos autores).

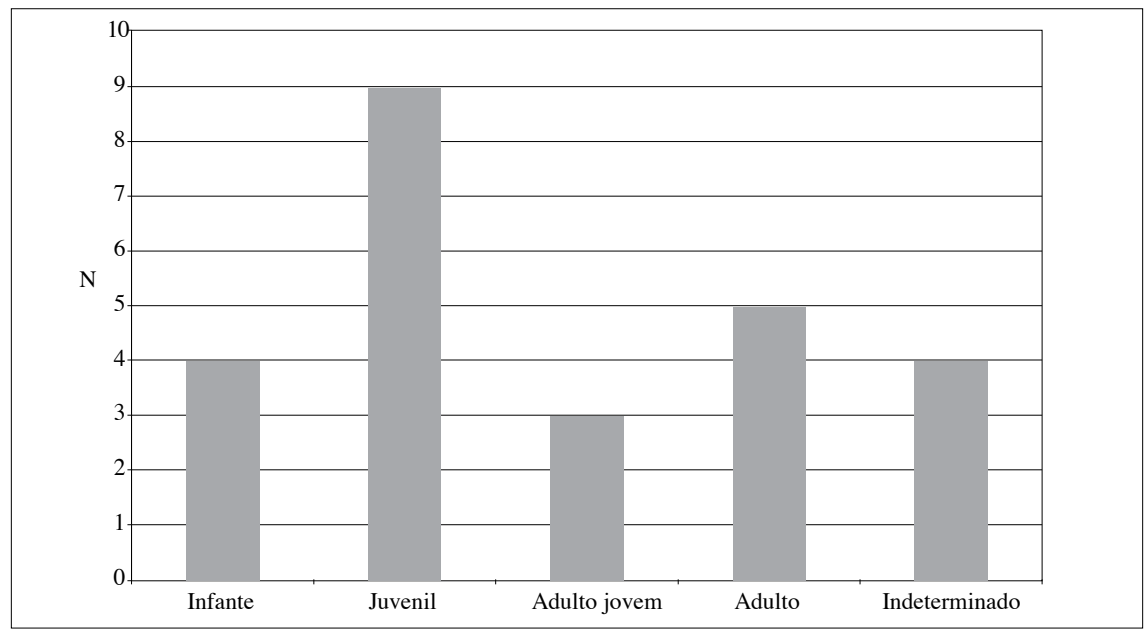

Figura 2. Distribuição dos vestígios osteológicos humanos atribuídos ao Paleolítico português por categoria etária. 
A distribuição dos dados ao longo dos vários períodos do Paleolítico, possibilita a compreensão de quais os sub-períodos melhor representados e, para tal, foram utilizadas as divisões temporais anteriormente definidas: "Paleolítico Inferior", "Paleolítico Médio" e "Paleolítico Superior". Os resultados são apresentados na Figura 3.

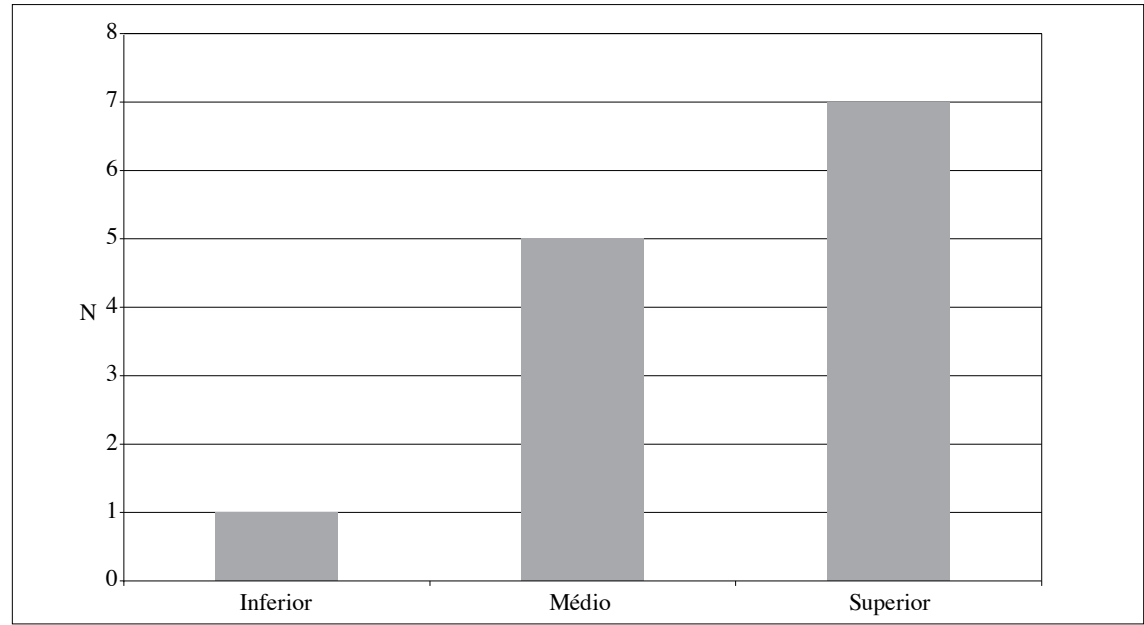

Figura 3. Distribuição dos vestígios osteológicos humanos identificados em território português ao longo dos três sub-períodos do Paleolítico.

A análise da distribuição cronológica remete-nos para um outro aspecto que importa compreender e que passa pela ocupação de diferentes espécies de hominíneos no território nacional. Ao longo do Paleolítico existiram na Europa, pelo menos, quatro espécies pertencentes ao género humano - Homo antecessor (1 milhão de anos - 800,000 anos), Homo heidelbergensis (500,000 anos - 180,000 anos), Homo neanderthalensis $(230,000$ anos - 28,000 anos) e Homo sapiens (40,000 anos - presente) (Arsuaga, 2003). No nosso país, tendo em conta a janela temporal compreendida entre os 210,000 anos e 10,000 anos deveria ser provável encontrar vestígios de Homo heidelbergensis, Homo neanderthalensis e Homo sapiens.

Em comum, os vestígios apresentam duas características: o facto de terem sido encontrados em contexto de gruta e, em termos geográficos, se centralizarem na zona da Estremadura portuguesa. As grutas permitem, tanto ao nível da preservação quanto ao nível da metodologia de prospecção, uma maior eficácia na recuperação de material ósseo. A limitação do espaço, 
bem como a sua protecção em relação aos agentes externos que provocam alterações tafonómicas e degradam o espólio osteológico, são factores determinantes para a elevada frequência deste material em grutas.

Na Figura 4 apresentamos a distribuição geográfica em Portugal dos diferentes sítios arqueológicos que debitaram restos ósseos humanos; esta será útil para a compreensão dos contextos ecológicos onde se poderá encontrar ocupação humana Pré-histórica.

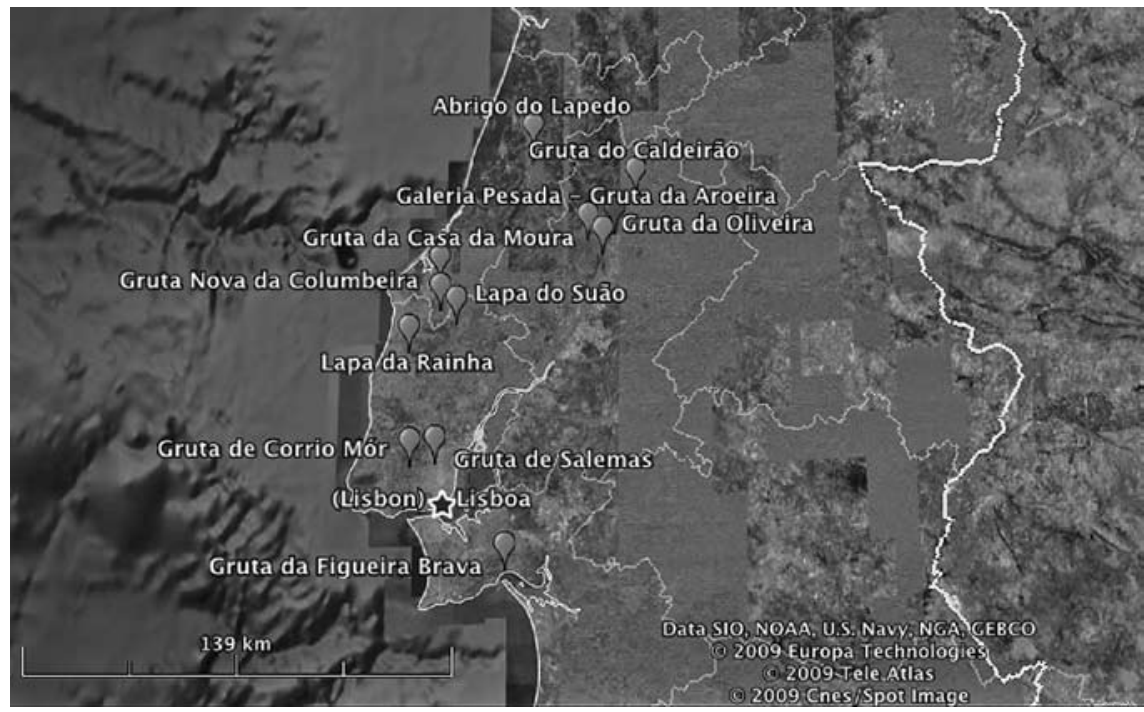

Figura 4. Distribuição dos vestígios osteológicos humanos do Paleolítico pelo território português (adaptado de Google, 2009).

\section{Discussão}

Os elementos recolhidos relativos a estes vestígios osteológicos, variam muito de acordo com o momento da sua descoberta. Se os contextos estudados mais recentemente se baseiam numa metodologia de campo e de laboratório que permite a conservação de todos os elementos que conduzem a uma interpretação mais precisa do passado, os estudos mais remotos são condicionados pelas práticas amadoras que perduraram no meio arqueológico nacional até meados do século passado. Por esse motivo existe uma dualidade ao nível das informações que este acervo oferece, sendo que os artigos científicos mais recentes consultados para a realização deste trabalho são 
muito mais elucidativos do que os mais antigos. Apesar da natureza perecível das peças esqueléticas, a escassez de vestígios osteológicos pode também estar associada a uma preferência pelo material arqueológico considerado durante muito tempo mais informativo do que o antropológico.

A análise paleodemográfica indica que estamos perante uma série osteológica em que os materiais mais comuns são as peças dentárias. As suas características de maior resistência e consequente maior durabilidade concorrem para a sua maior representatividade (Mays, 1998). A estimativa da idade à morte revelou uma maior frequência de indivíduos sub-adultos, podendo este facto estar relacionado com o elevado número de dentes encontrado. Este tipo de material antropológico permite a realização de estimativas da idade à morte mais próximas da realidade, já que apresentam características morfológicas distintas de acordo com as várias etapas do desenvolvimento fisiológico (White, 2000). A estimativa do número mínimo de indivíduos desta amostra, varia entre os 49 (48 fragmentos e 1 enterramento primário) e os 24 indivíduos (Cruz, 2007).

Cronologicamente esta série apresenta uma característica interessante na medida em que existe uma coincidência entre a distribuição dos vestígios pelos vários períodos do Paleolítico e as diversas espécies de hominíneos. Em parte, estes elementos podem estar relacionados com a ocupação tardia dos Neandertais no território nacional. Se em regiões mais centrais e orientais da Europa, o número de vestígios de Neandertais se reduz significativamente a partir dos 40,000 anos, na Península Ibérica o padrão de ocupação destes hominíneos é ligeiramente diferente, já que persistiram até mais tarde havendo, por isso, um maior número de restos osteológicos.

A concentração dos vários vestígios numa região bastante limitada geograficamente, a Estremadura portuguesa, nos distritos de Leiria, Santarém, Lisboa e Setúbal, suscita algumas questões. Quando se compara esta localização com os restantes sítios arqueológicos pré-históricos em que foram identificados níveis de ocupação atribuídos ao Paleolítico, este problema torna-se ainda mais intrigante. É possível que a natureza das grutas desta região, seja mais favorável à preservação do material osteológico. Se a Norte é compreensível a escassez de vestígios osteológicos, dada a geologia e o tipo de solos mais ácidos que caracterizam essa região e que são nefastos para a preservação deste tipo de material, já a Sul não parecem existir justificações desta natureza, sendo esta área conhecida por permitir boas preservações em campo. Importa, também, referir que ao nível dos vestígios arqueológicos 
atribuídos ao Paleolítico a sua dispersão geográfica é bem maior e abrange a quase totalidade dos distritos portugueses (Cruz, 2007).

Tendo ainda em consideração a distribuição geográfica dos vestígios osteológicos do Paleolítico na Península Ibérica, verificamos que o panorama espanhol é bastante diferente, já que se encontram dispersos por diversas longitudes e latitudes, apesar de estarem essencialmente em regiões costeiras (Figura 5).



Figura 5. Distribuição dos vestígios osteológicos humanos atribuídos ao Paleolítico na Península Ibérica (adaptado de Google, 2009).

A existência de uma continuidade geomorfológica e climática ao nível da Península Ibérica que se estabelece longitudinalmente levaria a crer que seria possível encontrar vestígios a diferentes latitudes (Ninyerola et al., 2005). Não obstante, é de referir um ponto em comum nestes dois territórios: a proximidade dos sítios arqueológicos à zona litoral. Tendo em conta este aspecto seria de esperar que o panorama que se verifica no lado espanhol se equiparasse ao território nacional, mas, contudo, tal não se verifica (Garralda, 2005-2006).

Os dados recolhidos para este trabalho vieram também reforçar a hipótese da ocupação e extinção tardia dos Neandertais. Se até há pouco tempo era comummente aceite que estes hominíneos se teriam extinguido há 40,000 
anos, hoje em dia a data mais provável para o seu desaparecimento andará em torno dos 28,000 anos (Finlayson et al., 2006). Em Portugal são três os sítios com vestígios de Neandertal com datações inferiores a 30,000 anos (Gruta da Figueira Brava, Gruta Nova da Columbeira e Gruta de Salemas). A classificação taxonómica é corroborada pelo tipo de indústria, cultura material e fauna associada. Alguns autores, como Zilhão (2000) e Raposo (1993a), têm sugerido - ainda que com pontos de vista diferentes - que as penínsulas europeias apresentarão um padrão de ocupação e de utilização do espaço consideravelmente diferente do que se verifica no resto do território da Europa Central. Ao encontro desta teoria, vão os dados recolhidos em Portugal e Espanha, assim como os vestígios recuperados no Cáucaso (Vindija), pois apresentam as datações mais tardias para a existência de Neandertais e da prevalência da indústria Mustierense (Smith et al., 1999; Zilhão, 2000).

Tendo em conta todos estes elementos, a relevância do acervo préhistórico do material osteológico, mostra-se importante para a compreensão do processo evolutivo humano nos últimos 200,000 anos, uma vez que poderá ser desmistificador de questões relacionadas com o ambiente, com o clima e com o modo de vida dos nossos antepassados mais recentes.

\section{Considerações finais}

Em Portugal, a Antropologia Física acompanhou as tendências científicas do resto da Europa e da América do Norte que se traduziram num forte desenvolvimento e interesse entre os finais do século XIX e até aos anos 40 do século XX. Foi essencialmente nas últimas décadas destes séculos que se descobriram a maior parte dos vestígios que hoje constituem o acervo osteológico humano atribuído ao Paleolítico português (Cunha, 1982; Cunha, 2002). Este facto está na base da discrepância ao nível das metodologias utilizadas no momento da prospecção e da análise dos vestígios, bem como na qualidade científica das publicações.

Os dados aqui apresentados permitem ilustrar a Pré-história mais remota do nosso país. Favorecem também a compreensão do papel do território português, em particular, e da Península Ibérica, no geral, no processo evolutivo humano. A natureza dos vestígios encontrados é idêntica à verificada noutros contextos pré-históricos - pequenos fragmentos osteológicos e peças dentárias - que, apesar de limitarem a análise paleodemográfica, 
permitem a par de outras áreas do conhecimento, aceder a indícios do passado, os quais não estariam acessíveis, tais como a estimativa da idade à morte e a distribuição dos indivíduos por classes etárias. Contudo, seria interessante perceber o motivo da concentração dos vestígios osteológicos na Estremadura. É provável que seja um problema decorrente da geologia e das características dos solos, como já foi referido, mas também pode resultar de uma prospecção limitada e intensa, aparentemente associada aos principais centros de investigação em arqueologia - Lisboa e Porto. No futuro seria interessante expandir as áreas de prospecção integrando nas equipas científicas responsáveis, técnicos de outras áreas afins - como seja a Antropologia - evitando desta forma a perda de informação.

\section{Bibliografia}

Almeida, F.; Santos, M. F.; Roche, J.; Veiga Ferreira, O. 1970. Notícia preliminar sobre as escavações na Lapa da Rainha (Vimeiro). Separata das Actas das I Jornadas Arqueológicas, Lisboa, Associação dos Arqueólogos Portugueses, 1970: 1-9.

Antunes, M. T. 1990-1991. O Homem da Gruta da Figueira Brava (ca. 30000): contexto ecológico, alimentação, canibalismo. Memórias da Academia das Ciências de Lisboa - Classe de Ciências, 31: 487-536.

Antunes, M. T.; Cardoso, J. L. 2000. Gruta Nova da Columbeira, Gruta das Salemas and Gruta da Figueira Brava: stratigraphy and chronology of the Pleistocene deposits. Memórias da Academia das Ciências de Lisboa: Classe de Ciências, 38: 23-67.

Arsuaga, J. L. 1999. El collar del Neandertal: en busca de los primeros pensadores. Madrid, Temas de Hoy.

Arsuaga, J. L. 2001. El enigma de la esfinge: las causas, el curso y el propósito de la evolución. Barcelona, Plaza \& Janés Editores, S. A. Col. Areté.

Arsuaga, J. L. 2003. Atapuerca: donde el tiempo remansa. National Geographic España edición especial - la evolución del hombre: de África a Atapuerca: 2-28.

Bicho, N. F. 2006. Manual de arqueologia pré-histórica. Lisboa, Edições 70.

Cardoso, J. L. 2002. Pré-história de Portugal. Lisboa, Editorial Verbo.

Cunha-Ribeiro, J. P. 1990. A Pré-história. In: Serrão, J.; Marques, A. H. O. (eds). Nova História de Portugal. Lisboa, Presença: 17-74. 
Cunha, A. X. 1982. Contribution à l'Histoire de l'Anthropologie physique au Portugal. Contribuições para o Estudo da Antropologia Portuguesa, 11: 1-56.

Cunha, E. 2002. Antropologia física e paleoantropologia em Portugal: um balanço. Arqueologia e História, 54: 261-272.

Cruz, C. B. 2007. Histórias de ossos no tempo das pedras: caracterização e estudo dos vestígios osteológicos do Paleolítico Português. Dissertação de Mestrado em Evolução Humana. Departamento de Antropologia, Universidade de Coimbra.

Delgado, N. 1867. Da existência do Homem no nosso solo em tempos mui remotos: Notícia ácerca das Grutas da Cesareda. Commissão Geológica de Portugal Estudos Geológicos, Primeiro opúsculo: 1-138.

Duarte, C.; Mauricio, J.; Pettit, P. S.; Trinkaus, E.; Van der Plicht, H; Zilhão, J. 1999. The early upper paleolithic human skeleton from Abrigo do Lagar Velho (Portugal) and modern human emerge in Iberia. Proceedings of the National Academy of Sciences, 96: 7604-7609.

Ferembach, D. 1962. La deuxième molaire déciduale inférieure de la grotte de Salemas (Portugal). Comunicações dos Serviços Geológicos, 46: 177-187.

Ferembach, D. 1964-1965a. La molaire humaine inférieure moustérienne de Bombarral (Portugal). Comunicações dos Serviços Geológicos, 48: 185-191.

Ferembach, D. 1964-1965b. Les ossements humains de Salemas (Portugal). Separata Comunicações dos Serviços Geológicos, 48: 5-25.

Finlayson, C.; Pacheco, F. G.; Rodríguez-Vidal, J.; Fa, D. A.; López, J. M. G.; Pérez, A. S.; Finlayson, G.; Allue, E.; Preysler, J. B.; Cáceres, I.; Carrión, J. S.; Jalvo, Y. F.; Gleed-Owen, C. P.; Espejo, F. J. J.; López, P.; Sáez, J. A. L.; Cantal, J. A. R.; Marco, A. S.; Guzman, F. G.; Brown, K.; Fuentes, N.; Valarino, C. A.; Villapando, A.; Stringer, C. B.; Ruiz, F. M.; Sakamoto, T. 2006. Late survival of the Neanderthals at the southernmost extreme of Europe. Nature, 5195: 1038-1041.

Garralda, M. D. 2005-2006. Los Neandertales en la Peninsula Ibérica. MUNIBE (Antropologia - Arkeologia), 57: 289-314.

Jones, S.; Martin, R.; Pelbean, D. 1992. The Cambridge encyclopedia of human evolution. Cambridge, Cambridge University Press.

Jurmain, R.; Kilgore, L.; Trevathan, W.; Nelson, H. 2004. Introduction to Physical Anthropology. Belmont, Wadsworth.

Lewin, R.; Foley, R. A. 2004. Principles of human evolution. Malden, Blackwell. Mays, S. 1998. The archaeology of human bones. London, Routledge. 
Ninyerola, M.; Pons, X.; Roure, J. M. 2005. Atlas Climático Digital da Península Ibérica: metodologia y aplicaciones en bioclimatologia y geobotância. Barcelona, Universitat Autonoma de Barcelona.

Penalva, C.; Veiga Ferreira, O. 1979. Nota sobre uma lasca-núcleo da Lapa da Rainha (Vimeiro). Revista Guimarães, 89: 265-273.

Raposo, L. 1993a. O Paleolítico. In: Medina, J. (ed.). História de Portugal. Vol. 1. Amadora, Ediclube: 21-99.

Raposo, L. 1993b. O Paleolítico médio. In: Carvalho, G.S.; Ferreira, A.B.; SennaMartinez, J.C. (eds.). O quaternário em Portugal: balanço e perspectivas. Lisboa, Edições Colibri: 147-161.

Raposo, L.; Cardoso, J. L. 1998. Las industrias líticas de la Gruta Nova de Columbeira (Bombarral, Portugal) en el contexto del Musteriense final de la Península Ibérica. Trabajos de Prehistoria, 55(1): 39-62.

Rocha, M. A. 1978. Dents permanentes de la Grotte de Lapa do Suão, Portugal. Contribuições para o Estudo da Antropologia Portuguesa, 10: 87-101.

Smith, F. H.; Trinkaus, E.; Pettitt, P. B.; Karavanic, I.; Paunovic, M. 1999. Direct radiocarbon dates for Vindija G1 and Velika Pecina Late Pleistocene hominid remains. Proceedings of National Academy of Sciences, 96 (22): 1228112286.

Trinkaus, E.; Bailey, S. E.; Zilhão, J. 2001. Upper Paleolithic human remains from the Gruta do Caldeirão, Tomar, Portugal. Revista Portuguesa de Arqueologia, 4: 5-17.

Trinkaus, E.; Marks, A. E.; Burgal, J-P.; Bailey, S. E.; Rink, W. J.; Richter, D. 2003. Later middle Pleistocene human remains from the Almonda karstic system, Torres Novas, Portugal. Journal of Human Evolution, 45: 219-226.

Trinkaus, E.; Maki, J.; Zilhão, J. 2007. Middle Paleolithic human remains from the Gruta da Oliveira (Torres Novas), Portugal. American Journal of Physical Anthropology, 134: 263-273.

Veiga Ferreira, O. 1984. O mais importante nível de ocupação do caçador Neandertal da Gruta Nova da Columbeira, Bombarral. In : Volume d'hommage au géologue Georges Zbyszewski à l'occasion de son passage à la retraite, 22 Octobre 1979. Paris, Éditions Recherche sur les Civilisations: 365-370.

White, T. 2000. Human osteology. San Diego, Academic Press.

Zbyszewski, G.; Veiga Ferreira, O.; Leitão, M.; North, C. T. 1987. O Paleolítico da Gruta de Correio Môr (Loures). Setúbal Arqueológica, 8: 7-27. 
Zilhão, J. 1993. As origens da Arqueologia Paleolítica em Portugal e a obra metodologicamente precursora de J. F. Nery Delgado. Arqueologia e história, 3 : 3-17.

Zilhão, J. 1997. O Paleolítico Superior da Estremadura portuguesa. Lisboa, Edições Colibri.

Zilhão, J. 2000. The Ebro frontier: a model for the late extinction of Iberian Neanderthals. In: Sringer, C.; Barton, R. N. E.; Finlayson, J. C. (eds.). Neanderthals on the edge. Oxford, Oxford books: 111-121.

Zilhão, J.; Trinkaus, E. 2002. Introduction. Zilhão, J.; Trinkaus, E. (eds.). In: Portrait of the artist as a child: the gravettian human skeleton from the Abrigo do Lagar Velho and its archeological context. Lisboa, Instituto de Arqueologia: 11-12.

Zilhão, J.; Maurício, J.; Souto, P. 1991. A arqueologia da Gruta do Almonda (Torres Novas). Resultado das escavações de 1988-89. In: Actas das IV Jornadas Arqueológicas. Lisboa, Associação dos Arqueólogos Portugueses: 161-166.

Zilhão, J.; Maurício, J.; Souto, P. 1993. Jazidas arqueológicas do sistema cársico da nascente do Almonda. Nova Augusta, 7: 35-54.

Artigo recebido a 12 de Dezembro de 2008 e aceite a 26 de Janeiro de 2009. 